\title{
Preparation and labeling of thienopyrimidine and environmental remediation of by-products
}

\author{
N. R. A. El-Mouhty ${ }^{1}$, Wesam S. Shehab ${ }^{2 *}$ and H. M. H. Gad ${ }^{3}$ \\ ${ }^{I}$ Faculty of Science, Department of Chemistry, Taif University. Taif, 21974, Kingdom of Saudi Arabia. \\ Labelled Compounds Department, Radioisotopes Production and Radioactive Sources Division, Hot Laboratories Center, Atomic \\ Energy Authority, P.O. Box 13759, Egypt. \\ ${ }^{2}$ Faculty of Pharmacy, Department of Pharmaceutical Chemistry, Taif University, Taif, 21974, Kingdom of Saudi Arabia. \\ Department of Chemistry, Faculty of Science, Zagazig Universty, Zagazig , 44511,Egypt. \\ ${ }^{3}$ Analytical Chemistry Department and Environmental Control, Hot Laboratories Center, Egyptian Atomic Energy Authority, P.O. \\ Box 13759, Egypt. \\ *Corresponding author E-mail: dr_wesam123@yahoo.com
}

\begin{abstract}
Thienopyrimidine was prepared using dehydrative cyclisation of phenylisothiocyanate with 4-aminopent-3-en-2-one (enaminone) in presence of dry acetone and Raioiodinated was performed using Chloramine-T and hydrogen peroxide methods as oxidizing agents. The conditions of radioiodination such as concentration of oxidizing agent, reaction time, concentration of thienopyrimidine and effect of $\mathrm{pH}$ were studied to get maximum yield. The optimum conditions for radioiodinations using chloramine-T method were $10 \mu \mathrm{g}$ Thienopyrimidine, $12 \mu \mathrm{g}$ chloramine $-\mathrm{T}$ and 1 minute reaction time at $\mathrm{pH}$ 7.4. The optimum conditions for radioiodination using hydrogen peroxide method were $10 \mu \mathrm{g}$ Thienopyrimidine, $10 \mu$ l hydrogen peroxide: acetic acid (1: 1) and 5 minutes reaction time at $\mathrm{pH}$ 7.4. In all cases, the by-products were removed using activated carbon to prevent the environmental threats.
\end{abstract}

Keywords: Thienopyrimidine, radioiodinations, chloramine-T, hydrogen peroxide, activated carbon.

\section{Introduction}

The 5-substituted pyrimidines and their nucleoside derivatives have been the subject of many studies mainly due to their elevated antiviral and anticancer activities. On the other hand, the functionalization of the 6-position of pyrimidines showed important anti-HIV-1 activity and antirubella virus activity a verity of anticancer drugs made from pyrimidine derivatives are currently in clinical use, as for example some of these compounds applied successfully for the treatment of several neoplastic diseases such as leukemia and testicular cancer. While the effect of anticancer drugs on solid tumors is weak, the hydrazinopyrimidine-S-carbonitrile derivatives have antitumoral activity. Also, pyrimidine derivatives are very well known in medicinal chemistry for their therapeutic applications, analgesic antihypertensive, antipyretic and anti-inflammatory drugs.

In view of the pharmacological importance of thienopyrimidine and in continuation of our previous work on the synthesis of biologically active pyrimidines and thienopyrimidines, the synthesis of 5-acetyl-6-methyl-2-phenyl pyrimidine-4-thiol 3 have been achieved by the dehydrative cyclization of phenylisothiocyanate $\mathbf{1}$ with 4-aminopent-3en-2-one 2 (enaminone).

Several methods are used for radioiodination of thienopyrimidine electrophilic substitution reaction using different oxidizing agent such as chloramines-T method [1,21]", lactoperoxidase method [22]", iodogen method [19,22]" and Nbromosuccinimide method . 


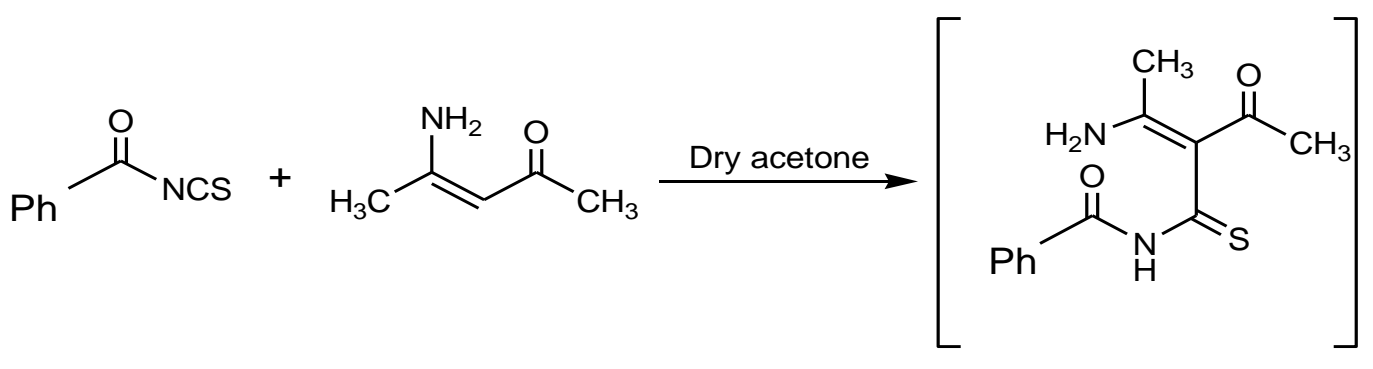<smiles>CC(=O)c1c(C)nc(-c2ccccc2)nc1S</smiles>

Two different procedures for the radioiodination of thienopyrimidine were investigated. The objective of the present study was to find the most efficient method to provide an adequate and suitable preparation of radioiodinated tracer. The two different procedures were chloramine-T oxidation method (Ch-T) [1]" and hydrogen peroxide method [22]". The two procedures were optimized empirically and then assessed for efficiency of incorporation of ${ }^{125} \mathrm{I}$, for the degree of radioiodination damage and the standardization of different parameters of radioiodination was investigated.

Environmental pollution as a consequence of technological evolvement has become one of the most crucial problems of the century [25]". Pharmaceuticals like antibiotics used in the remedy of many infections are considered as a group of water and wastewater pollutants [26]". The presence of antibiotics in pharmaceuticals companies' wastes and hospitals flowing out streams and their entrance into surface or underground water has posed two influential risks. First, occurrence of these materials in the environment itself is a threat (as an organic compounds) and finally their entrance into environment follows the risk of microorganism resistance, which means not only is their effect as a cure lost, but also they become a problem themselves [25]".

In spite of intensive requirement to clean the water and waste water from these antibiotics, there is no specific sorbent with high sorption capacity recorded for this purpose. In fact most of the removal methods are biological methods such as using activated sludge or biodegradation procedures [27,28]", although other methods like filtration, membrane, ion exchange, ionic treatment, using activated carbon as sorbent and electrochemical methods are applied [29,30,31,32,33]". Hydrophobic surface and high specific area are two main features of activated carbon, making it good sorbents for keeping vast amounts of compounds on their surface [35]". Extraction and sorption of amino acids, proteins, phenolic compounds, tetracyclins, sulphonamides and cephalosporins are examples of adsorbed materials by Carbon Nano Tubes [36, 37]".

In this work, our local prepared activated carbon [4]" is subjected to treatment of aqueous solution including by-product of the preparation and labeling of thienopyrimidine. Our aim is to find the capable and economical new sorbent to remove these antibiotics from waste water, then the effect of some parameters on the sorption process will be studied in our future work to understand the isotherms and kinetics investigations.

\section{Materials and methods}

\section{Materials:}

Sodium salt and hydrogen peroxide $\left(\mathrm{H}_{2} \mathrm{O}_{2}\right)$ were purchased from Sigma Chemical Co. Iodine-125 was purchased from Radiochemical International Inc.,Canada, as a no-carrier added solution in diluted $\mathrm{NaOH}$. All other chemicals were of analytical grade.

\section{Methods:}

1- Chloramine-T (Ch-T) method: 
This method was used as previously developed by [1]" but modified by limiting the amount of Ch-T used to prevent excessive oxidation. For the labeling procedure, $10 \mu \mathrm{g}$ of thienopyrimidine in $10 \mu 10.05 \mathrm{M}$ phosphate buffer, $\mathrm{pH} 7.4$ were added to about $5 \mu \mathrm{g} 1$ of $\mathrm{Na}^{125} \mathrm{I}(1 \mathrm{mCi}, 37 \mathrm{MBq})$ in a reaction vial. This mixture was stirred then $10 \mu 1$ of buffer solution containing the desired amount of Ch-T was added to carry out the reaction. After a given time, the reaction was stopped by adding $10 \mu \mathrm{l}$ of sodium metabisulfite $(20 \mathrm{mg} / \mathrm{ml})$.

\section{2- Hydrogen peroxide method:}

A sample of $5 \mu \mathrm{l} \mathrm{Na}{ }^{125} \mathrm{I}$ solution $(1 \mathrm{mCi}, 37 \mathrm{MBq})$ was pipette into the reaction vessel then $10 \mu \mathrm{g}$ of thienopyrimidine in $10 \mu \mathrm{l}$ phosphate buffer $(0.05 \mathrm{M}, \mathrm{pH} 7.4)$ was added and the reaction was started by the addition of $10 \mu 1$ of freshly prepared solution of $\mathrm{H}_{2} \mathrm{O}_{2}$ :acetic acid (1:1). The mixture was agitated on a vortex mixer. The reaction was allowed to be carried out for different time intervals then stopped by adding $10 \mu \mathrm{l}$ of sodium metabisulfite $(20 \mathrm{mg} / \mathrm{ml})$.

\section{Chromatographic analysis:}

The products were analyzed by the paper electrophoresis method using $0.05 \mathrm{M}$ phosphate buffer ( $\mathrm{pH} 7.4$ ). The radioiodination yield was calculated as the ratio of the radioactivity of the labeled product to the total radioactivity:

$$
\text { Radioiodination yield } \%=\frac{\text { activity of the product } \times 100}{\text { Total activity }}
$$

Purification of the radiolabelled thienopyrimidine was carried out by gel filtration over a1X30 cm column packed with sephadex G-100. One $\mathrm{ml}$ fractions were collected in tubes containing $1 \mathrm{ml}$ of $0.05 \mathrm{M}$ phosphate buffer -bovine serum albumin (BSA) buffer. Elution pattern was monitored by counting radioactivity of fractions in a well type NaI(TI) scintillation counter. Fractions containing protein were pooled together and diluted to $4 \mu \mathrm{Ci} / \mathrm{ml}$ in assay buffer. One ml solution was dispensed in vial, freeze-dried and stored at $+40 \mathrm{C}$. At the time of using, the contents were reconstituted in $10 \mathrm{ml}$ of assay buffer. Alternatively, the tracers were diluted to $0.4 \mu \mathrm{Ci} / \mathrm{ml}$ and $10 \mathrm{ml}$ volumes were dispensed and stored at $-200 \mathrm{C}$ until these tracers were used in assay.

\section{Results and discussion}

The experiments were performed in detail by following the electrophillic substitution reaction to establish an ideal iodination procedure without causing the thienopyrimidine to lose its biological properties.

The purification step is mandatory to separate the labeled thienopyrimidine from the free iodide, other reactant and damaged material. Several techniques are currently available like ion -exchange, adsorption, electrophoresis and high performance liquid chromatography (HPLC) but the most widely technique is gel filtration [17]". The elution pattern of

${ }^{125}$ I-thienopyrimidine using gel chromatography on a sephadex G-100 fine column are shown in figures (1) and (2).

\section{Factors affecting the radioiodination of thienopyrimidine}

\section{- Effect of reaction time:}

It was found that the optimum reaction time for the radioiodination by chloramines $-\mathrm{T}$ method to obtain maximum yield was $1 \mathrm{~min}$. compared to $5 \mathrm{~min}$ by hydrogen peroxide method (table 1). The results of chloramines-T method were in agreement with the data of [23]". 


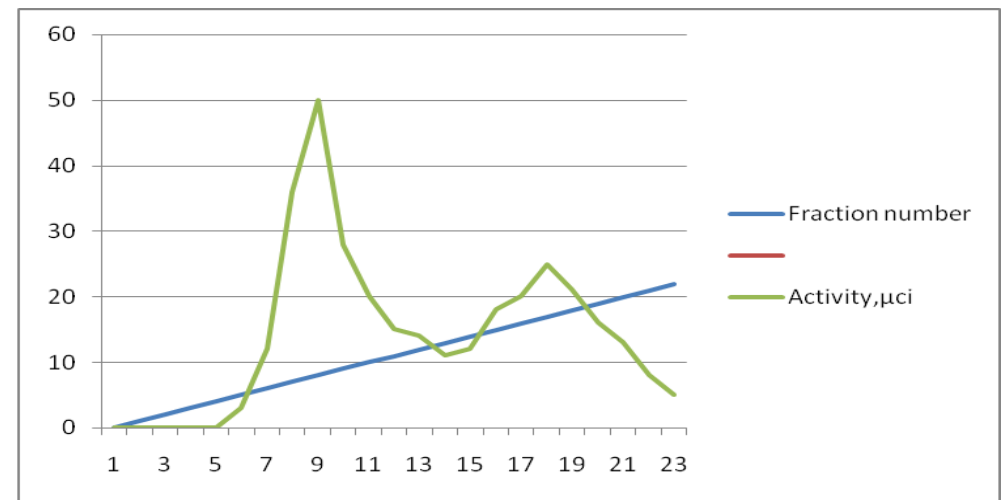

Fig. 1: Elution pattern of $\mathrm{I}^{125}$ Thienopyrimidine - using gel Chromatography on sephadex G-100 Column $(\mathrm{Ch}-\mathrm{T}$ method $)$.

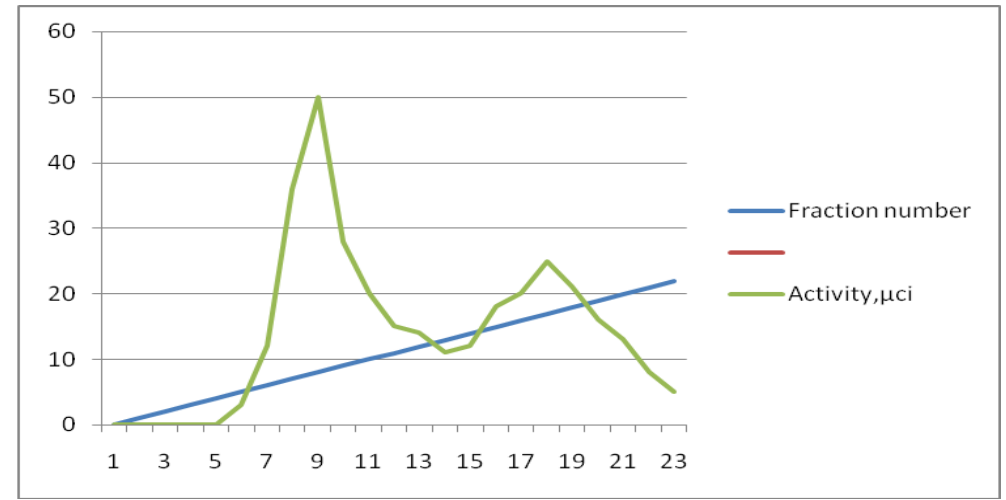

Fig. 2: Elution pattern of $\mathrm{I}^{125}$ - Thienopyrimidine using gel Chromatography on sephadex G-100 Column $\left(\mathrm{H}_{2} \mathrm{O}_{2}\right.$ method $)$

Table 1: Effect of reaction time on radioiodination of Thienopyrimidine

\begin{tabular}{|l|l|}
\hline Reaction time (min) & Iodination yield \% \\
\hline 0.25 & 35.2 \\
0.5 & 42.1 \\
1 & 47,6 \\
5 & 45.2 \\
10 & 41.3 \\
\hline Hydrogen peroxide & \\
1 & 28.2 \\
5 & 42.4 \\
10 & 35.1 \\
15 & 28.9 \\
30 & 25 \\
\hline
\end{tabular}

Table 2: Effect of $\mathrm{pH}$ on the radioiodination of Thienopyrimidine

\begin{tabular}{|l|l|l|}
\hline \multirow{2}{*}{$\mathrm{pH}$} & Iodination yield \% \\
\cline { 2 - 3 } & Ch-T method & $\mathrm{H}_{2} \mathrm{O}_{2}$ method \\
\hline 4.0 & 25.5 & 21.9 \\
\hline 6.3 & 40.2 & 37.5 \\
\hline 7.4 & 47.6 & 42.4 \\
\hline 8.0 & 38.1 & 34.2 \\
\hline
\end{tabular}

\section{- Effect of pH:}

The radioiodination methods were carried out at $\mathrm{pH}$ values 4,6.3,7.4 and 8 respectively. The data obtained are summarized in table (2). It was observed that $\mathrm{pH} 7.4$ was the most suitable value for all iodination experiments . This 
can be explained by the fact that between $\mathrm{pH} 7$ and 8, the aromatic ring is activated for electrophilic attack owing to the electron donating effect of the neighbouring cyanide group .

\section{- Effect of the amount of oxidizing agent:}

Table (3) shows the effect of chloramines-T amount on the radioiodination of thienopyrimidine From this table, it was found that the optimum amount of chloramines $-\mathrm{T}$ was $12 \square \mathbf{g}$ to obtain maximum yield. These results are in agree with the results obtained by [1]" who suggestthat the decrease of Radioiodination yield with higher chloramines -T content can be attributed to destructive side reactions and oxidation damage of thienopyrimidine .

Table 3: Effect of the amountof chloramines $-\mathrm{T}$ on the radioiodination of Thienopyrimidine
\begin{tabular}{|c|c|}
\hline Amount of Ch-T $(\mu \mathrm{g})$ & Yield \% \\
\hline 3 & 25.6 \\
\hline 6 & 45.0 \\
\hline 12 & 47.6 \\
\hline 24 & 43.2 \\
\hline
\end{tabular}

Table 4: Effect of $\mathrm{H}_{2} \mathrm{O}_{2}$ : acetic acid on the radioiodination of Thienopyrimidine.

\begin{tabular}{|c|c|}
\hline $\mathrm{H}_{2} \mathrm{O}_{2}:$ Acetic acid & Iodination yield \% \\
\hline $1: 0.5$ & 25.6 \\
\hline $1: 1$ & 42.4 \\
\hline $1: 2$ & 38.7 \\
\hline $1: 3$ & 35.1 \\
\hline
\end{tabular}

Table 5: Effect of $\mathrm{H}_{2} \mathrm{O}_{2}$ : acetic acid volume on the radioiodination of Thienopyrimidine

\begin{tabular}{|c|c|}
\hline Volume $(\mu \mathrm{l})$ & Iodination yield \% \\
\hline 5 & 30.2 \\
\hline 10 & 42.4 \\
\hline 20 & 36.3 \\
\hline 30 & 23.6 \\
\hline
\end{tabular}

To reduce iodination damage, the mild oxidizing agent $\mathrm{H}_{2} \mathrm{O}_{2}$ was used to prevent the formation of side products as in the case of chloramines-T. According to data in table (4), it was found that the optimum ratio of $\mathrm{H}_{2} \mathrm{O}_{2}$ : acetic acid was $1: 1$ to obtain maximum yield. Also, the optimum volume of $\mathrm{H}_{2} \mathrm{O}_{2}$ : acetic acid was $10 \mu \mathrm{l}$ to obtain maximum yield as shown in table (5).

\section{- Effect of substrate content:}

The dependence of the radioiodination yield on the concentration of thienopyrimidine was studied at different amount of thienopyrimidine (table6). The results show that the yield was independent of thienopyrimidine content when the amounts of thienopyrimidine quantity studied was in the range of 5-15 $\mu$ g using chloramines-T and hydrogen peroxide methods, so $5 \mu \mathrm{g}$ of thienopyrimidine was used for all experiment.

Table 6: Effect of quantity of Thienopyrimidine on its iodination by ${ }^{125} \mathrm{I}$.

\begin{tabular}{|l|l|l|}
\hline \multirow{2}{*}{$\begin{array}{l}\text { Thienopyrimidine } \\
\text { quantity }(\mu \mathrm{g})\end{array}$} & Iodination yield, \% \\
\cline { 2 - 3 } & Ch-T method & $\mathrm{H}_{2} \mathrm{O}_{2}$ method \\
\hline 5 & 47.6 & 42.4 \\
\hline 10 & 48.2 & 43.0 \\
\hline 15 & 49.0 & 43.5 \\
\hline
\end{tabular}

\section{Environmental remediation of waste produced}

Surface hydrophobicity is one of the most important chemical properties of activated carbon which causes a wide range of materials and compounds adsorption on the surface of these structures. In this work, by considering the characteristic of our prepared [7]" activated carbon, its ability in adsorption of thienopyrimidine antibiotics and other by-products from aqueous solution has been investigated. Batch experiment was done and the effect of contact time was studied [30]". 


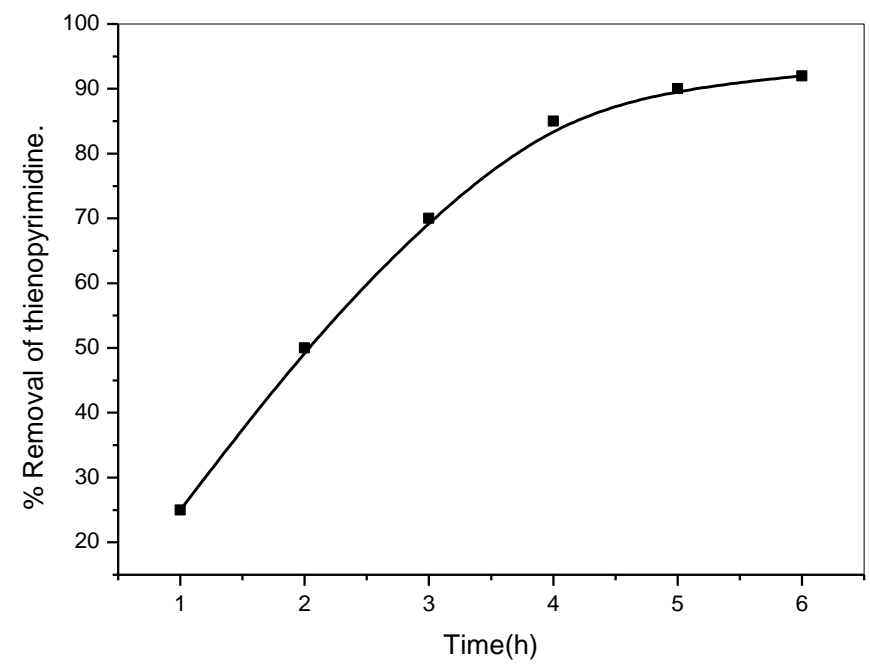

Fig. 3: Effect of contact time on the \% removal of iodine labeled thienopyrimidine.

The \% removal of iodine labeled thienopyrimidine using prepared activated carbon was measured by batch adsorption experiments. The $\mathrm{pH}$ of experiments was adjusted to 7.0. In the batch adsorption experiment, the adsorbent was added to a known volume of the iodine labeled thienopyrimidine solution, and was stirred at $298 \mathrm{~K}$ for interval times. The sample solution was separated from the adsorbent by centrifugation [34]. The remaining activity of iodine labeled thienopyrimidine was determined by gamma counter. The percentage sorption was calculated from the following equation:

$$
\% \text { Sorption }=[(\mathrm{Ai}-\mathrm{A}) / \mathrm{Ai}] \times 100 .
$$

Figure 3 showing the relation between contact time and \% removal of iodine labeled thienopyrimidine. As a result, a direct association is observed among these two factors at first, which means there is an increase in \% removal as the contact time increases and after some time \% removal rate changes more slowly and ultimately since reaching equilibrium time it remained unmoving. Time $5 \mathrm{hr}$ is chosen as equilibrium time. The details of most important parameters on sorption process and desorption studies will be investigated in our next future work.

\section{References}

[1] Hunter, W.M. and Greenwood, F.C., Labelling of hormones. Nature, 194,495 (1962).

[2] Lednicer, D. and Mitscher, L.A., The organic chemistry of drug synthesis; pergamon press; NY, 1980; Vol. 2, p. 79;

[3] Lednicer, D.; Mitscher, L.A., The organic chemistry of drug synthesis; pergamon press; NY, Vol. 3, p. 152 (1980).

[4] Gad H. M. H., El-Mouhty N. R. A., and Aly H. F., Applicability of Activated Carbon to Treatment of Waste Containing Iodine-Labeled Compounds. Separation Science and Technology, 44: 681-711, 2009.

[5] Carlson, A.A., Nicol, L., Young,A.T., Parlow, A.F. and McNeilly, A.S.,General and comparative Endocrinology ,130,148-156 (2003).

[6] Demers, L.M., In: Titez fundamentals of clinical chemistry , Burtis,C.A.and Ashwood ,E.R. (Eds),5th ed., Philadelphia , WB Saunders Co.,p.822(2001).

[7] Edwards , R., Immuonoasasay of clinical chemistry , W.M.Hunter and J.E.T.Crrie (Eds) , 2nd ed., Churchill Livingstone, Edinburgh ,p.139(1983).

[8] Edwards, R., Lalloz, M. and Pull,P.I. In: immunoassay for clinical chemistry , W.M.Hunter and J.E.T.Corrie (Eds). 2nd ed., Churchill Livingstone, Edinburgh, p.277 (1983).

[9] El-Kolaly,M.T.,, Mehany, N.L.,Ayyoub,S.M. and Hassan, S.E.M., Arab J.Nucl. Sci.Appli.,38(3),241 (2005)

[10] Braschi, I., S. Blasioli, et al., 2009. Removal of sulfonamide antibiotics from water: evidence of adsorption into an organophilic zeolite Y by its structural modifications. J. Hazardous Materials.

[11] Andreozzi, R., M. Canterino, et al., 2005. Antibiotic removal from wastewaters: The ozonation of amoxicillin. J. Hazardous Materials, 123: 243-250.

[12] Urase, T. and T. Kikuta, 2005. Separate estimation of adsorption and degradation of pharmaceutical substances and estrogens in the activated sludge process. Water Res., 39(7): 1289-1300.

[13] Yu, T.H., A.Y.C. Lin, et al., 2009. Removal of antibiotics and non-steroidal anti-inflammatory drugs by extended sludge age biological process. Chemosphere, 77(2): 175-181.

[14] Kunin, R., S. Vetrano, et al., 1990. A novel approach to the use of ion exchange and adsorption media for the processing of pharmaceutical and biological substances. Reactive Polymers, 13(3): 291-298.

[15] Carlesi Jara, C., D. Fino, et al.. 2007. Electrochemical removal of antibiotics from wastewaters. Applied Catalysis B: Environmental, 70(1-4): $479-487$. 
[16] Kosutic, K., D. Dolar, et al., 2007. Removal of antibiotics from a model wastewater by RO/NF membranes. Separation and Purification Technol., 53(3): 244-249.

[17] Choi, K.J., S.G. Kim, et al., 2008. Removal of antibiotics by coagulation and granular activated carbon filtration. J. Hazardous Materials, 151(1): 38-43.

[18] Yu, Z., S. Peldszus, et al., 2008. Adsorption characteristics of selected pharmaceuticals and an endocrine disrupting compound--Naproxen, carbamazepine and nonylphenol--on activated carbon. Water Res., 42(12): 2873-2882.

[19] Redding, A.M., F.S. Cannon, et al., 2009. A QSAR-like analysis of the adsorption of endocrine disrupting compounds, pharmaceuticals and personal care products on modified activated carbons. Water Res., 43(15): 3849-3861.

[20] Niu, H., Y. Cai, et al., 2007. Evaluation of carbon nanotubes as a solid-phase extraction adsorbent for the extraction of cephalosporins antibiotics, sulfonamides and phenolic compounds from aqueous solution. Analytica Chimica acta, 594(1): 81-92.

[21] Fang, G.Z., J.X. He, et al., 2006. Multiwalled carbon nanotubes as sorbent for on-line coupling of solid-phase extraction to high-performance liquid chromatography for simultaneous determination of 10 sulfonamides in eggs and pork. J. Chromatography A 1127(1-2): 12-17.

[22] Maryam J., Seyed F. A. and Gholamreza K., 2011. Batch Adsorption of Cephalosporins Antibiotics from Aqueous Solution by Means of Multi-Walled Carbon Nanotubes World Applied Sciences Journal 14 (11): 1642-1650. 